\title{
DIOCTOFIMOSE EM UM CÃO PROVENIENTE DO MUNICÍPIO DE VALENÇA, RJ: RELATO DE CASO
}

\author{
Laís Zacaron MARQUES' ${ }^{1}$, Beatriz Abdalla Ferraz de BARROS ${ }^{1}$, Fabrício Nascimento GAUDÊNCIO ${ }^{1,2}$, \\ Cristiane Nunes Coelho da ROCHA ${ }^{2}$ \& Lilian Cristina de Sousa Oliveira BATISTA ${ }^{1 *}$
}

\begin{abstract}
1 Centro de Ensino Superior de Valença, Fundação Educacional Dom André Arcoverde, Faculdade de Medicina Veterinária de Valença, Valença, RJ, Brasil.

2 Universidade Federal Rural do Rio de Janeiro, Departamento de Parasitologia Animal, Seropédica, RJ, Brasil.

*Autor para correspondência: vet.lilianbatista@gmail.com
\end{abstract}

http://dx.doi.org/10.18571/acbm.116

\section{RESUMO}

Dioctophyma renale é o maior nematoide conhecido. Seu parasitismo tem sido descrito em várias espécies animais e no homem. Este helminto localiza-se preponderantemente no rim direito ou livre na cavidade abdominal de seus hospedeiros. Sinais clínicos como abatimento, inapetência e emagrecimento podem estar associados à dioctofimose, apesar do curso da parasitose ser muitas vezes assintomático nos animais e pessoas infectadas. O único tratamento eficaz é a remoção cirúrgica do parasito e, em alguns casos, do rim afetado. O presente trabalho teve como objetivo relatar um caso de parasitismo por Dioctophyma renale em um cão no município de Valença/RJ. Dado o diagnóstico através da urinálise e localização do parasito por ultrassonografia, optou-se pela remoção cirúrgica do rim afetado. Esta permitiu a detecção de dois parasitos que haviam feito com que o rim se tornasse uma cápsula fibrosa. Pode-se concluir que uma boa abordagem diagnóstica é fundamental para o sucesso no tratamento e que o exame ultrassonográfico é uma importante ferramenta complementar para a avaliação renal de cães acometidos por esse parasitismo.

Palavras chave: Dioctophyma renale; Parasitos; Rim.

\begin{abstract}
Dioctophyma renale is the largest known nematode. Its parasitism has been described in various animal species and man. This helminth is located predominantly in the right kidney or free in the abdominal cavity of their hosts. Clinical signs such as subsidence, loss of appetite and weight loss may be associated with dioctofimose, despite the course of parasitosis is often asymptomatic infected animals and people. The only effective treatment is surgical removal of the parasite and, in some cases, the affected kidney. This study aimed to report a case of parasitism by Dioctophyma renale in a dog in the municipality of Valença-RJ. The diagnosis was obtained through the urinalysis and the location of the parasite by ultrasonography. After this, it was proceeded the surgical removal of the affected kidney. This allowed the detection of two parasites that had caused the affected kidney to become a fibrous capsule. It can be concluded that a good diagnostic approach is fundamental for success in the treatment and that the ultrasound examination is an important complementary tool for the renal evaluation of dogs affected by this parasitism.
\end{abstract}

Keywords: Dioctophyma renale; Parasites; Kidney. 


\section{Introdução}

Dioctophyma renale é um helminto pertencente à família Dioctophymatidae, e à classe Nematoda (COTTAR et al., 2012; COLPO et al., 2007). É o maior nematoide conhecido, podendo o macho atingir 45 centímetros e a fêmea até 100 centímetros de comprimento (ALVES et al., 2007). Tem sido descrito em várias espécies animais e no homem, sendo mais frequente em cães não domiciliados e em canídeos silvestres, possivelmente por hábitos alimentares não seletivos (MAYRINK et al., 2000; KOMMERS et al., 1999; MONTEIRO et al., 2002).

Este nematoide localiza-se preponderantemente no rim direito ou livre na cavidade abdominal de seus hospedeiros, levando à destruição progressiva das camadas cortical e medular, reduzindo o órgão à uma cápsula fibrosa (LEITE et al., 2005). Geralmente só um rim é parasitado, fazendo com que o rim sadio sofra hipertrofia para compensar a inatividade do rim lesionado (ALVES et al., 2007). Os animais e o homem se infectam ingerindo carne de peixe mal cozida e anelídeos aquáticos parasitados com a forma larval (VARZONE et al., 2008).

Os sinais clínicos como abatimento, inapetência e emagrecimento podem estar associados à dioctofimose, apesar do curso da parasitose ser muitas vezes assintomático. As alterações variam de acordo com a localização, grau de desenvolvimento do parasito e a reação dos tecidos lesados, bem como a espécie parasitada (COLPO et al., 2007). O animal pode se apresentar apático, com latido rouco, marcha cambaleante e distúrbios nervosos. Não ocorrem sinais de insuficiência renal em casos de envolvimento unilateral (COTTAR et al., 2012). Em sua maior parte, os cães não apresentam sinais clínicos sugestivos do parasitismo por Dioctophyma renale (KOMMERS et al., 1999).

O diagnóstico pode ser feito de diferentes formas, dentre as quais está a pesquisa por ovos operculados de casca espessa e rugosa na urina através do exame parasitológico urinário (TAYLOR et al., 2010; BOWMAN, 2010). Também pode ser visualizado por radiografia (MONTEIRO et al., 2002) e em casos de necropsia os parasitos podem ser encontrados no hospedeiro (ALVES et al., 2007). A ultrassonografia é um método eficiente para evidenciar tal parasito (COTTAR et al., 2012).

O único tratamento eficaz é a remoção cirúrgica do parasito e, em alguns casos, do rim afetado (ALVES et al., 2007; SILVEIRA et al., 2009; KOMMERS et al., 1999; COTTAR et al., 2012).

Este trabalho teve como objetivo relatar um caso de parasitismo por D. renale em um cão do município de Valença-RJ.

\section{Relato de caso}

Um cão, macho, sem raça definida, adulto, pesando $15,6 \mathrm{Kg}$ foi encontrado em abril de 2014 no distrito de Barão de Juparanã, município de Valença-RJ. O animal foi resgatado por apresentar um tumor no membro posterior esquerdo e hérnia perianal, porém a caminho da Policlínica, onde seria realizado o primeiro atendimento, o animal apresentou um episódio de urina com odor fétido. A médica veterinária responsável pelo atendimento solicitou, inicialmente, alguns exames laboratoriais, como hemograma, bioquímicas séricas (ureia, creatinina, ALT e fosfatase alcalina) e urinálise a partir de urina coletada por sondagem uretral com sonda flexível.

No hemograma, o animal apresentou alterações sugestivas de discreta anemia arregenerativa e discreta leucocitose. No exame bioquímico observou-se elevação dos níveis séricos de ureia; enquanto creatinina, ALT e fosfatase alcalina apresentaram-se dentro dos parâmetros de normalidade. Na urinálise foi observado aumento da densidade urinária, cor acastanhada, $\mathrm{pH}$ ácido e aspecto turvo, proteinúria, hematúria, presença de algumas células descamativas de transição, inúmeros piócitos e presença de ovos compatíveis com os de D. renale. 


\section{Biomedica Brasiliensia}

ISSN: 2236-0867

Para confirmação do diagnóstico e localização do parasito, foi realizado um exame ultrassonográfico, onde foi possível observar o rim direito medindo 5,9 centímetros, irregular, apresentando forma alterada e parasitado por $D$. renale. O rim contralateral apresentava conformação normal, paredes regulares e relação córtico medular com definição.

Dado o diagnóstico e localização do nematoide, o animal foi encaminhado para a Policlínica de Pequenos Animais da Faculdade de Medicina Veterinária de Valença, onde optouse pela nefrectomia do rim afetado, visto que não havia presença deste helminto no rim contralateral e na cavidade abdominal.

Após a remoção cirúrgica do rim direito, foi observado que o mesmo havia se reduzido exclusivamente a uma cápsula fibrosa (Figura 1), preenchida por conteúdo sanguinolento. A presença de dois parasitos foi detectada dentro desta cápsula, sendo um macho e uma fêmea, com 16 e 26 centímetros de comprimento, respectivamente (Figura 2). O animal ficou em observação durante quatro horas após a cirurgia e por se apresentar hígido, obteve alta no mesmo dia.

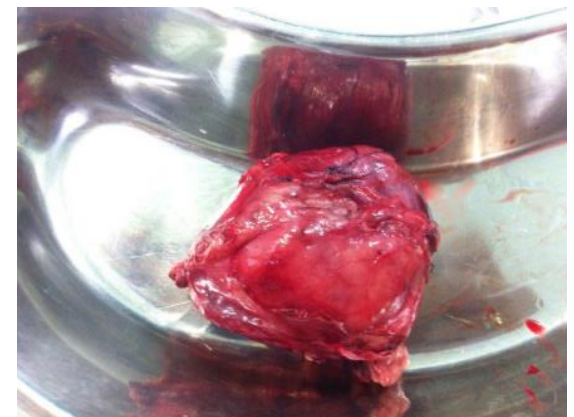

Figura 1 - Rim direito reduzido a uma cápsula fibrosa.

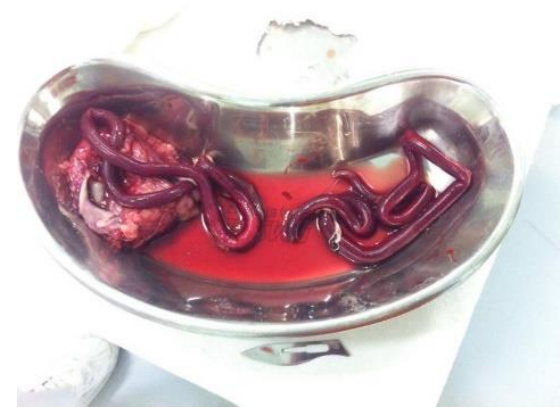

Figura 2 - Dioctophyma renale, macho à esquerda e fêmea à direita, encontrados no rim direito do cão.

\section{Discussão}

O animal não apresentava nenhum sinal clínico compatível com a dioctofimose, além do odor fétido da urina, o que condiz com o que foi relatado nos trabalhos de Zardo et al. (2012) e Monteiro et al. (2002). Alves et al. (2007) relataram que animais infectados podem apresentar apatia, prostração, emagrecimento, arqueamento do dorso, aumento de volume palpável na região renal e, em alguns casos, andar vacilante, podendo também ocorrer peritonite e uremia devido à insuficiência renal.

Os parasitos encontrados tinham 16 e 26 centímetros de comprimento, sendo macho e fêmea, respectivamente. Segundo Leite et al. (2005) os mesmos podem variar entre quinze centímetros à um metro de comprimento.

As lesões macroscópicas encontradas por Kommers et al. (1999) nos casos de parasitismo renal eram de atrofia moderada ou acentuada do parênquima associada à presença de um a três parasitos adultos. Ainda de acordo com o autor citado, na maioria dos casos havia exsudato necrohemorrágico na pelve. Nos casos de atrofia acentuada do parênquima renal, o rim era visto como uma saculação formada por parede lisa, delgada e fibrosa contendo os parasitos, corroborando o que foi encontrado neste relato.

Os parasitos encontrados neste estudo se localizavam no rim direito, coincidindo com o que foi relatado por Monteiro et al. (2002), Varzone et al. (2008) e Leite et al. (2005). Geralmente $D$. renale é encontrado no rim direito; acredita-se que essa maior incidência aconteça devido à sua proximidade com o duodeno (KOMMERS et al., 1999).

Tal como visto por Cottar et al. (2012), no presente relato pode-se observar alterações sugestivas de anemia arregenerativa no hemograma, através da contagem de hemácias $(5,01 \mathrm{x}$ $\left.10^{6} / \mu \mathrm{L}\right)$ e hematócrito $(36,76 \%)$, sem ter havido aumento do índice hematimétrico VCM. Porém, 
não foi realizada contagem de reticulócitos para que se pudesse confirmar ausência de resposta medular. Além disso, a redução foi discreta, frente aos valores de referência para a espécie. Segundo, Thrall et al. (2007), outros mecanismos compensatórios podem atuar em um primeiro momento para tentar compensar a perda inicial ou crônica de hemácias, como o aumento do 2,3difosfoglicerato e o aumento do débito cardíaco, sem aumentar significativamente o número de reticulócitos ao exame hematológico.

De acordo com Amaral et al. (2008) hematúria e proteinúria podem ocorrer, nos casos de dioctofimose, secundariamente a uma inflamação no trato urinário, o que pode ser observado no presente caso inclusive pela presença de inúmeros piócitos. Apesar de o helminto estar localizado no rim, não foi observado aumento de creatinina, apenas de ureia, diferente dos dados encontrados por Cottar et al. (2012), que através de um estudo retrospectivo de casos atendidos na Unidade Hospitalar para Animais de Companhia da Pontifícia Universidade Católica do Paraná, encontrou sete cães positivos para $D$. renale, dos quais 57,14\% apresentaram azotemia. Levando-se em consideração a compensação renal do órgão não afetado, somada às causas de aumento da concentração de ureia sanguínea não relacionadas necessariamente à um aumento na concentração de creatinina como mencionadas por Bush (2004), no presente relato, não se verificou a ocorrência de insuficiência renal em função do parasitismo.

O cão deste estudo foi resgatado na rua, portanto apresentava hábito alimentar pouco seletivo, o que corrobora as observações de Kommers et al. (1999), Mayrink et al. (2000), Colpo et al. (2007) e Cottar et al. (2012), que relataram que animais parasitados por D. renale frequentemente são animais de rua ou que têm acesso à mesma.

\section{Conclusão}

Pode-se concluir que uma boa abordagem diagnóstica é fundamental para o sucesso no tratamento e que o exame ultrassonográfico é uma importante técnica complementar para a avaliação renal de cães acometidos por esse parasitismo, principalmente no que se refere à identificação do rim acometido e para avaliação do rim contralateral, bem como para avaliar a integridade dos demais órgãos abdominais, fornecendo valiosas informações para o tratamento cirúrgico.

A presença de $D$. renale em um cão no município de Valença evidencia a necessidade de maiores estudos na região.

\section{Referências}

ALVES, G.C.; SILVA, D. T.; NEVES, M. F. Dioctophyma renale: O parasita gigante do rim. Revista Científica Eletrônica de Medicina Veterinária, v. 4, n. 8, p. 175-180, 2007.

AMARAL, L. C. D.; POLIZER, K. A.; SANT'ANA, T. M.; NEVES, M. F. Diocotphyma renale. Revista Científica Eletrônica de Medicina Veterinária, v. 6, n. 10, 2008. Disponível em: <http://faef.revista.inf.br/imagens_arquivos/arquivos_destaque/PO4WQrLxYTqj1Zd_2013-5-2910-26-30.pdf> Acesso em 18/12/2016.

BOWMAN, D. D. Georgis - Parasitologia Veterinária. 9ed. Rio de Janeiro: Elsevier, 2010. p. 209-210.

BUSH, B. M. Interpretação de resultados laboratoriais para clínicos de pequenos animais. São Paulo: ROCA LTDA, 2004. 376p. 
COLPO, B.C.; SILVA, A.S.; MONTEIRO, S.G.; STAINKI, D.R.; CAMARGO, D.G.; COLPO, E.T.B. Ocorrência de Dioctophyma renale em cães no município de Uruguaiana - RS. Revista da Faculdade de Zootecnia, Veterinária e Agronomia, v. 14, n. 2, p. 175-180, 2007.

COTTAR, B.H.; DITTRICH, G.; FERREIRA, A.A.; CARVALHO, A.C.P.; ALBERNAZ, V.G.P.; LUZ, M.T.; TASQUETI, U.I. Achados ultrassonográficos de cães parasitados por Dioctophyma renale - Estudo Retrospectivo. Revista Veterinária e Zootecnia, v.19, (Supl.1), p. 8-11, 2012.

KOMMERS, G.D.; ILHA, M.R.S.; BARROS, C.S.L. Dioctofimose em cães: 16 casos. Ciência Rural, v. 29, n. 3, p. 517-522, 1999.

LEITE, L.C.; CÍRIO, S.M.; DINIZ, J.M.F.; LUZ, E.; NAVARRO-SILVA, M.A.; SILVA, A.W.C.; LEITE, S.C.; ZADOROSNEI, A.C.; MUSIAT, K.C.; VERONESI, E.M.; PEREIRA, C.C. Lesões anatomopatológicas presentes na infecção por Dioctophyma renale (GOEZE, 1782) em cães domésticos (Canis familiaris, LINNAEUS, 1758). Archives of Veterinary Science, v. 10, n. 1, p. 95-101, 2005.

MAYRINK, K.C; PAES-DE-ALMEIDA, E.C; THOMÉ, S.M.G. Dioctophyma renale (GOEZE, 1782) em cães. Caderno Técnico Científico da Escola de Medicina Veterinária da Universidade do Grande Rio, Rio de Janeiro, v. 2, p. 20-40, 2000.

MONTEIRO, S.G.; SALLIS, E.S.V.; STAINKI, D.R. Infecção natural por trinta e quatro helmintos da espécie Dioctophyma renale (GOEZE, 1782) em um cão. Revista da FZVA, v. 9, n. 1, p. 95-99, 2002.

SILVEIRA, L.L.; LEMOS, L.S.; FERREIRA, F.S.; FREITAS, M.V.; PEREIRA, M.A.C.; CARVALHO, C.B. Avaliação entre as técnicas de centrífugo-sedimentação e sedimentação rápida (Paratest ${ }^{\circledR}$ ) na identificação de ovos de Dioctophyma renale em urina de cães. Jornal Brasileiro de Ciencia Animal, v. 2, n. 3, p. 150-158, 2009.

TAYLOR, M.A.; COOP, R.L.; WALL, R.L. Parasitas de cães e gatos. In: TAYLOR, M.A.; COOP, R.L.; WALL, R.L. Parasitologia Veterinária. 3ed, 2010, p. 363-364.

THRALL, M. Hematologia e Bioquímica Clínica Veterinária. $1^{a}$ ed. São Paulo: Ed. ROCA LTDA. 2007, 582p.

VARZONE, J.R.M.; AQUINO, L.P.C.T.; RODOVALHO, M.V.T. Achados macroscópicos de lesões resultantes do parasitismo por Dioctophyma renale em lobo-guará (Chrysocyon brachyurus) - Relato de Caso. Ensaio e Ciência: Ciências Biológicas, Agrárias e da Saúde, v. 12, n. 2, p. 171-178, 2008.

ZARDO, K.M.; SANTOS, D.R.; BABICSAK, V.R.; BELOTTA, A.F.; OLIVEIRA, H.S.; ESTANISLAU, C.A.; MAMPRIM, M.J.; BRANDÃO, C.V.S. Aspecto ultrassonográfico da dioctofimose renal canina. Revista Veterinária e Zootecnia, v. 19, (Supl. 1), p. 57-60, 2012. 